\title{
Thin-film ZnO as Micromechanical Actuator at Low Frequencies
}

\author{
F R BLOM, D J YNTEMA, F C M VAN DE POL, M ELWENSPOEK, J H J FLUITMAN and TH J A POPMA
}

Faculty of Electrical Engineering, Unwersity of Twente, $P O$ Box 217, 7500 AE Enschede (The Netherlands)

\begin{abstract}
A new model is proposed for the low-frequency piezoelectric activity of $\mathrm{ZnO}$ films grown on CVD $\mathrm{SiO}_{2}$ In this MOS structure, with $\mathrm{ZnO}$ as the semiconductor, a depletion layer is induced by means of a $\mathrm{d} c$ bias voltage Using standard semiconductor theory, an expression is derived relating the electric field in this depletion layer with the driving a $c$ and $d c$ voltages Due to the built-in charge at the $\mathrm{ZnO}-\mathrm{SiO}_{2}$ interface, a depletion layer exists, even when no d c bias is applied We measured the vibration amplitude at resonance of the tip of a silicon cantilever, upon which the MOS structure was deposited, as function of a $c$ and $d c$ voltages The results show good agreement with calculated curves Therefore, it can be concluded that thin-film $\mathrm{ZnO}$ can be used as a prezoelectric actuator for micromechantcal devices working at low frequencies
\end{abstract}

\section{Introduction}

Thun-film $\mathrm{ZnO}$ is a very promising material for electromechanical transducers, since it has high piezoelectric coupling factors [1] Unfortunately, there are several problems with this material The most severe problem anses from the conductivity due to excessive zinc, which prevents any electric field bulding up in the film at low frequencies The cut-off frequency is determined by the relaxation time $\tau$, given by the product of the resistivity $\rho$ and the permitivity $\varepsilon$ of the material [2] Consequently, $\mathrm{ZnO}$ films can easily be used above $1 \mathrm{MHz}$ and therefore thin-film $\mathrm{ZnO}$ is often used as a piezoelectric transducer in the field of SAW and $\mathrm{BAW}$ resonators (see, e $\mathrm{g}$ refs 2 and 3 )

At low-frequency applications, however, the build-up of an electric field is counteracted by charge transport of free carriers In the literature, solutions for this problem have been sought by increasing the resistivity of the film by doping with, for instance, lithium [2], or by encapsulating the $\mathrm{ZnO}$ film between insulating $\mathrm{SiO}_{2}$ layers, hence cutting off electric leakage paths $[4,5]$ The explanation Muller et al $[4,5]$ give for the lowfrequency activity of their $\mathrm{ZnO}$ films is the Debye length, $L_{\mathbf{D}}$, being much larger than typical film thicknesses of 120 and $1 \mu \mathrm{m}$, respectively This explanation is not valid for our $\mathrm{ZnO}$ films grown on $\mathrm{CVD} \mathrm{SiO}_{2}$ as we have determined a much smaller value for $L_{\mathrm{D}}$, namely $L_{\mathrm{D}}=5 \mathrm{~nm}$ [6] However, earlier work in our group on micromechantcal sensors demonstrated the low-frequency activity of $\mathrm{ZnO}$ films as prezoelectric transducers $[7,8]$

In this paper we propose an explanation for the low-frequency activity of $\mathrm{ZnO}$ films, based on standard semiconductor theory (see ref 9) and the electric model for these layers, which is described elsewhere [6]

\section{Model}

A sputtered $\mathrm{ZnO}$ film can be treated as a polycrystalline semiconductor Low-frequency application of this prezoelectric material requires a depletion layer inside the semiconducting film to sustain an electric field, for instance by means of an MOS structure The width of this depletion layer can be calculated as a function of the applied d c voltage from standard semiconductor theory When the electnc field is known, the electromechanical transduction of the piezoelectric effect can be calculated

In the following, we shall apply this simple strategy to a $\mathrm{ZnO}$ film grown on $\mathrm{CVD} \mathrm{SiO}_{2}$, an MOS structure, depicted in Fig 1 Also in this Figure the space charge distribution and the electric field in the different layers are shown, if a negative d c voltage, $U_{\mathrm{DC}}$, is apphed Using Poisson's equation we can calculate the electric field in every region Integrating over the complete MOS structure, we derive the relation for the width of the depletion layer as a function of $U_{D C}$, $W_{\mathrm{d}}\left(U_{\mathrm{DC}}\right)$ On this $\mathrm{d} \mathrm{c}$ voltage we superpose an a c signal, $U_{\mathrm{AC}}$, which is so small that $W_{\mathrm{d}}$ is not influenced In this case the electric field in the depleted $\mathrm{ZnO}, E_{z}$, vanes proportionally to $U_{\mathrm{AC}}$ In order to determine the relation between $E_{\mathrm{z}}$ and 

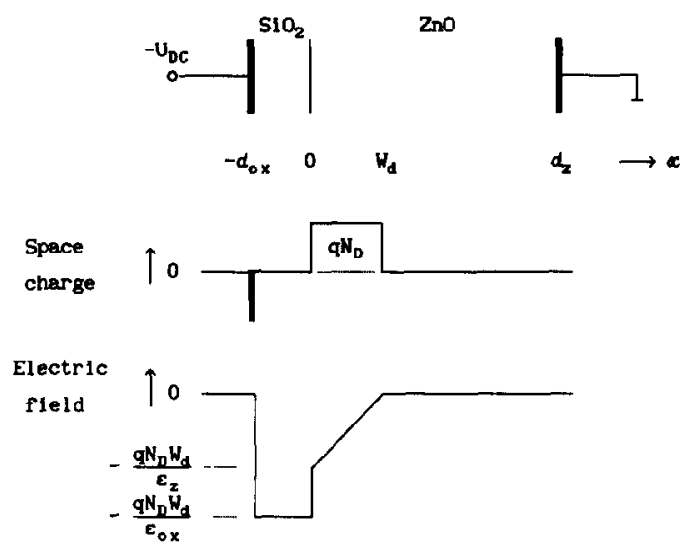

Fig 1 Cross section of the $\mathrm{SiO}_{2}-\mathrm{ZnO}$ MOS structure with the space charge distribution and the electric field in the different regions if a negative $d c$ voltage is applied

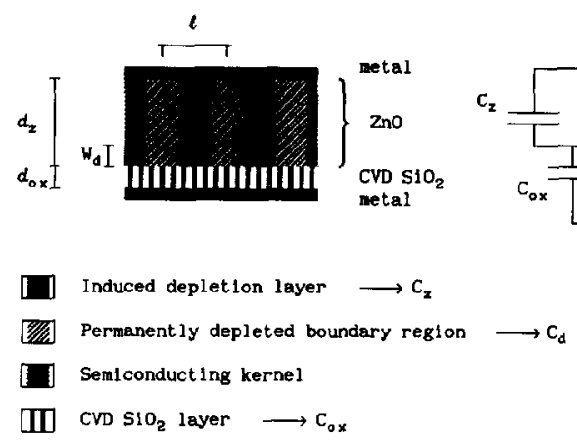

Fig 2 Schematic drawing of the MOS structure, showing the columnar structure of the $\mathrm{ZnO}$ layer with the permanently depleted boundary region, the semiconducting kernel and the mduced depletion layer in the kernel Also important parameters and the equvalent circust are shown

$U_{\mathrm{AC}}$, we have to take a closer look at the film structure

Our $\mathrm{ZnO}$ films consist of columnar grains, containing a semiconducting kernel surrounded by a permanently depleted boundary region [6] This is schematically depicted in Fig 2 The equivalent circuit of the MOS structure then consists of three capacitors, one corresponding to the $\mathrm{SiO}_{2}$ layer, $\mathrm{C}_{\mathrm{ox}}$, one to the boundary region, $\mathrm{C}_{\mathrm{d}}$, and one due to the induced depletion layer in the kernel, $C_{z}$ With the ald of this circuit we can calculate the relation between $U_{\mathrm{AC}}$ and $E_{\mathrm{z}}$, which is also dependent on $U_{\mathrm{DC}}$, thus $E_{\mathrm{z}}=f\left(U_{\mathrm{DC}}\right) U_{\mathrm{AC}}$

\section{Measurement Method and Sample Structure}

In order to determine the piezoelectric activity of the $\mathrm{ZnO}$ films, we used a micromachined silicon cantilever with an MOS structure deposited top, see Fig 3 This multilayer structure is excited into a bending mode vibration by the piezoelectric effect in the depletion layer The vibration amplitude of the tip of the cantilever at resonance is measured with a heterodyne Mach Zehnder interferometer, which allows an absolute determination of the amplitude

The cantilevers are $5 \mathrm{~mm}$ long, 02 to $05 \mathrm{~mm}$ wide and 15 to $25 \mu \mathrm{m}$ thick, depending on the batch used The $\mathrm{ZnO}$ film is reactively sputtered in a planar RF magnetron system from a pure $\mathrm{Zn}$ target using $100 \% \mathrm{O}_{2}$ The $\mathrm{ZnO}$ is $05 \mu \mathrm{m}$, the $\mathrm{SiO}_{2} 015 \mu \mathrm{m}$ thick, respectively Molybdenum is used as the bottom electrode, aluminium as the top electrode material The tip of the cantilever is not deposited with thin films and serves as a mirror for the optical detection

A relation is now denved for the deflection of the tip of the silicon cantilever with an MOS structure deposited on top, due to the piezoelectric activity in the $\mathrm{ZnO}$, see $\mathrm{F}_{\mathrm{ig}} 3$ As a first order we shall approximate the activity of the complete $\mathrm{ZnO}$ layer with that of a layer having a thickness $W_{d}$ only The electric field is applied over this thickness, resultıng in a mean stress in the $\mathrm{ZnO}$ The real stress distribution in the $\mathrm{ZnO}$ layer is much more complicated, of Fig 2, and a three-dimensional analysis is required to solve this problem Our approximation results in neglecting the upper part of the $\mathrm{ZnO}$ layer

Since the thickness of the $\mathrm{ZnO}$ layer, $d_{2}$, is much smaller than that of the silicon cantilever, $d_{\mathrm{s}}$, we find a simple relation between the dynamic vibration amplitude of the cantilever at resonance as function of the driving $\mathrm{a} c$ and $\mathrm{d} c$ voltages

$\delta=3 Q \frac{Y_{z}}{Y_{\mathrm{s}}}\left(\frac{l_{3}}{d_{\mathrm{s}}}\right)^{2} \quad d_{31} U_{\mathrm{AC}} f\left(U_{\mathrm{DC}}\right)$

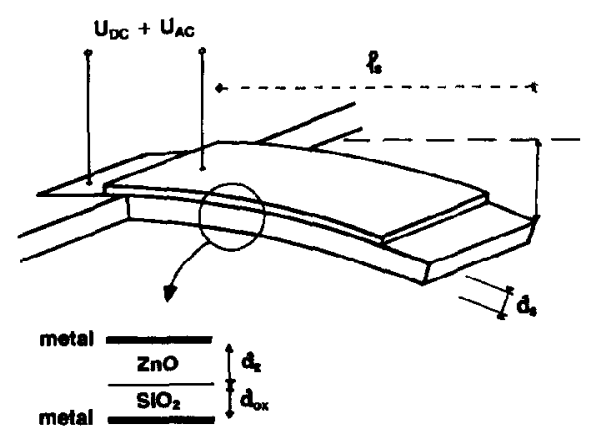

si

Fig 3 The multilayered cantilever in vibrationary deflection with a close-up the cross section of the $\mathrm{S}_{1} \mathrm{O}_{2}-\mathrm{ZnO}$ MOS structure on top of the silicon 
where $Q, Y_{\mathrm{z}}, Y_{\mathrm{s}}, l_{\mathrm{s}}$ and $d_{31}$ are, respectively, the mechanical quality factor, the Young's modulus of $\mathrm{ZnO}$ and of $\mathrm{St}$, the length of the cantilever and the prezoelectric coefficient of $\mathrm{ZnO}$

\section{Results and Discussion}

Results of measurements of the vibration amplitude of the tip of the cantilever as a function of $U_{\mathrm{AC}}$ and $U_{\mathrm{DC}}$ are shown in Fig 4 The theoretical curves, calculated according to eqn (1), are drawn as well In these calculations the bulk value of the prezoelectric coefficient $d_{31}$ is used, namely $d_{31}=-51 \times 10^{-12} \mathrm{~m} / \mathrm{V} \quad[10]$ The mechanical quality factor of the cantilever is $95 \pm 10$

In Fig 4 it is seen that the measured results agree quite well with the calculated curves $\delta$ is proportional to $U_{\mathrm{AC}}$ and varies with $U_{\mathrm{DC}}$ in accordance to our model We also observe $\delta$ remaining constant for $U_{\mathrm{DC}}$ below $-4 \mathrm{~V}$ In this case inversion occurs at the $\mathrm{ZnO}-\mathrm{SlO}_{2}$ interface and the depletion layer in the $\mathrm{ZnO}$ has reached its maximum width This effect is not accounted for in the calculations

Furthermore, we observe an off-set in the d c voltage of $7 \pm 1 \mathrm{~V}$, which is due to interface charge at the $\mathrm{ZnO}-\mathrm{SiO}_{2}$ interface This shift is in agreement with the results of $C-V$ measurements, where a mean flat-band voltage was found of $5 \pm 1 \mathrm{~V}$ [6] An important conclusion of this observation is that no external $d c$ voltage is required to use the piezoelectric effect $\mathrm{We}$ can also apply this explanation to the results of Muller et al $[4,5]$ As outlined above, they encapsulated their $\mathrm{ZnO}$ films between insulating $\mathrm{SiO}_{2}$ layers Because of the interface charge, they found low-frequency prezoelectric activity of the $\mathrm{ZnO}$

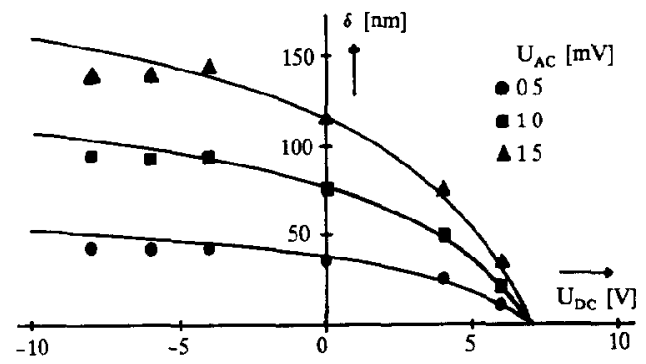

Fig 4 Measured $(\boldsymbol{O}, \boldsymbol{\boldsymbol { D }}, \boldsymbol{\Delta})$ and calculated (full line) values of the vibration amplitude $\delta$ of the tip of the cantilever at resonance as a function of $\mathrm{d} c$ and a $\mathrm{c}$ voltages

\section{Conclusions}

In this paper we propose a new model explaining the low-frequency application of semiconducting $\mathrm{ZnO}$ films Using an MOS structure with $\mathrm{ZnO}$ as the semiconductor, a depletion layer is induced by means of a d c voltage The electric field in this layer is proportional to the driving a $c$ voltage Because of a built-in charge at the $\mathrm{ZnO}-\mathrm{SiO}_{2}$ interface, a depletion layer exists, even when no $d c$ bias is applied Therefore, $\mathrm{ZnO}$ thin films can be applied as piezoelectric transducers for micromechanical devices working at low frequencies

\section{Acknowledgements}

The authors would like to thank Siebe Bouwstra for stımulating discussions and John Baxter for carefully reading the manuscript This research in the program of the Foundation of Fundamental Research on Matter (FOM) is sponsored by the Dutch Technology Foundation (STW)

\section{References}

1 T Shiosaki and A Kawabata, Prezoelectric thin films for SAW applications, Ferroelectrics, 42 (1982) 219-232

2 T Shiosak 1 and A Kawabata, Low-frequency piezoelectnctransducer applications of $\mathrm{ZnO}$ film, Appl Phys Lett, 25 (1974) 10

3 S Ono, $K$ Wasa and S Hayakawa, Surface-acoustic-wave properties in $\mathrm{ZnO}-\mathrm{SiO}_{2}-\mathrm{S}$ layered structure, Wave Electron, 3 (1977) 35

4 D L Polla and R S Muller, Zinc oxude thin films for integrated sensor applications, Tech Digest, IEEE SolidState Sensors Workshop, Hilton Head Island, SC, U S A, June 6-9, 1986

5 P L Chen, R S Muller, $\mathbf{R}$ M White and $\mathbf{R}$ Jolly, Thin film $\mathrm{ZnO}$-MOS transducer with virtually $\mathrm{DC}$ response, Proc IEEE Ultrasonics Symp , Boston, MA, U S A , Nov 1980, p 945

6 F R Blom, F C M van de Pol, G Bauhus and Th J A Popma, Electric model and electric properties of sputtered polycrystalline Zno films, Thin Solid Films, submitted for publication

7 J G Smits, $H$ A C Tilmans, $K$ Hoen, $H$ Mulder, J van Vurren and $G$ Boom, Resonant diaphragm pressure measurement system with ZnO on S1 excitation, Sensors and Actuators, 4 (1983) 565-571

$8 \mathrm{~S}$ Bouwstra, Scanner-research, third phase of the Integrated Laser Beam Deflector project, Internal Rep 070 1055, Unversity of Twente, 1986 (in Dutch)

9 e g, S M Sze, Semiconductor Devices, Physics and Technology, Wley, New York, 1st edn, 1985, pp 186-195, R S Muller and T I Kamins, Device Electronics for Integrated Circuits, Wiley, New York, 2nd edn , 1986, pp 378-394

10 K -H Hellwegeı (ed ), Landolt and Börnstem. Numerical Dasa and Functional Relationships in Science and Technolagy, Vol III-11, Sprnnger, Berlın, 1979, p 370 